\title{
Correction to: High Conductivity Al-Si-Mg Foundry Alloys-Market, Production, Optimization and Development
}

Takeshi Saito, Petter Åsholt, Leonhard Heusler, Thomas Balkenhol, and Kjetil R. Steen

\section{Correction to:}

Chapter "High Conductivity Al-Si-Mg Foundry Alloys-Market,

Production, Optimization and Development"

in: C. Chesonis (ed.), Light Metals 2019,

The Minerals, Metals \& Materials Series,

https://doi.org/10.1007/978-3-030-05864-7_34

The original version of the book was inadvertently published with incorrect unit in Figure 1 of Chapter 34. The unit has been changed from seconds [sec] to minutes [min].

The erratum chapter has been updated with the change. 